\title{
Erratum to: Benefit from anthracyclines in relation to biological profiles in early breast cancer
}

\author{
Andrea Rocca - Sara Bravaccini - Emanuela Scarpi · Anita Mangia • \\ Stella Petroni - Maurizio Puccetti - Laura Medri • Luigi Serra • Monica Ricci • \\ Serenella Cerasoli $\cdot$ Nicoletta Biglia $\cdot$ Roberta Maltoni • Donata Casadei Giunchi • \\ Lorenzo Gianni · Amelia Tienghi · Mario Brandi · Marina Faedi • \\ Piero Sismondi · Angelo Paradiso · Rosella Silvestrini · Dino Amadori
}

Published online: 19 February 2014

(C) Springer Science+Business Media New York 2014

\section{Erratum to: Breast Cancer Res Treat}

DOI 10.1007/s10549-013-2819-0

In the original publication of the article, one of the coauthor's name was given incorrectly as Monica Faedi. The author's correct name is Marina Faedi.

The online version of the original article can be found under doi:10. 1007/s10549-013-2819-0.

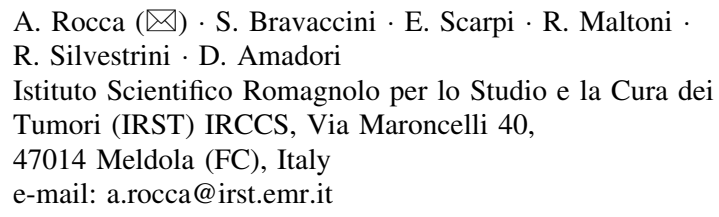

A. Mangia - S. Petroni - M. Brandi - A. Paradiso National Cancer Research Centre, Istituto Tumori "Giovanni Paolo II", Bari, Italy

M. Puccetti · A. Tienghi

Santa Maria delle Croci Hospital, Ravenna, Italy

L. Medri $\cdot$ L. Serra $\cdot$ D. C. Giunchi

Morgagni-Pierantoni Hospital, Forlì, Italy

M. Ricci · L. Gianni

Infermi Hospital, Rimini, Italy

S. Cerasoli · M. Faedi

Bufalini Hospital, Cesena, Italy

N. Biglia $\cdot$ P. Sismondi

University of Turin, A.O. Mauriziano "Umberto I" Hospital,

Turin, Italy 